\title{
Effect of Heparin-induced Lipolysis on the Distribution of Apolipoprotein E among Lipoprotein Subclasses

\author{
Studies with Patients Deficient in Hepatic Triglyceride Lipase and Lipoprotein Lipase
}

\author{
Ardon Rubinstein, Joyce Corey Gibson, James R. Paterniti, Jr., Gary Kakis, Alick Little, \\ Henry N. Ginsberg, and W. Virgil Brown \\ Department of Medicine, Division of Arteriosclerosis and Metabolism, Mount Sinai School of Medicine, New York, New York 10029; \\ St. Michael's Hospital, Toronto, Ontario M5S, 2J5, Canada
}

\begin{abstract}
In normal subjects, apolipoprotein $\mathbf{E}$ (apo $E$ ) is present on very low density lipoproteins (VLDL) (fraction I) and on particles of a size intermediate between VLDL and low density lipoproteins (LDL) (fraction II). The major portion of apo $\mathbf{E}$ is, however, on particles smaller than LDL but larger than the average high density lipoproteins (HDL) (fraction III). To investigate the possible role of the vascular lipases in determining this distribution of apo $\mathrm{E}$ among the plasma lipoproteins, we studied subjects with primary deficiency of either hepatic lipase or of lipoprotein lipase and compared them with normal subjects. Subjects with familial hepatic triglyceride lipase deficiency $(n=2)$ differ markedly from normal in that fraction II is the dominant apo E-containing group of lipoproteins. When lipolysis of VLDL was enhanced in these subjects upon release of lipoprotein lipase by intravenous heparin, a shift of the apo $E$ from VLDL into fractions II and III was observed. In contrast, apolipoproteins CII and CIII (apo CII and CIII, respectively) did not accumulate in intermediate-sized particles but were shifted markedly from triglyceride rich lipoproteins to HDL after treatment with heparin. In subjects with primary lipoprotein lipase deficiency $(n=4)$, apo $E$ was confined to fractions I and III. Release of hepatic triglyceride lipase by heparin injection in these subjects produced a shift of apo $E$ from fraction I to III with no significant increase in fraction II. This movement of apo $E$ from large VLDL and chylomicronsized particles occurred with little hydrolysis of triglyceride and no significant shift of apo CII or CIII into HDL from triglyceride rich lipoproteins.

When both lipoprotein lipase and hepatic triglyceride lipase were released by intravenous heparin injection into normal subjects $(n=3)$, fraction I declined and the apo $E$ content of fraction III increased by an equivalent amount. Either moderate or no change was noted in the intermediate sized particles (fraction II). These data strongly support the hypothesis that fraction II is the product of the action of lipoprotein lipase upon triglyceride rich lipoproteins and is highly dependent on hepatic triglyceride lipase for its further catabolism. In addition,
\end{abstract}

This work was presented in preliminary form at the Scientific Sessions of the American Heart Association, Anaheim, CA, November 1983.

Received for publication 14 November 1983 and in revised form 11 July 1984.

J. Clin. Invest.

(C) The American Society for Clinical Investigation, Inc. 0021-9738/85/02/0710/12 \$1.00

Volume 75, February 1985, 710-721 the hydrolysis by hepatic triglyceride lipase of triglyceride rich lipoproteins in general results in a preferential loss of apo $\mathbf{E}$ and its transfer to a specific group of large HDL.

\section{Introduction}

Apolipoprotein $\mathrm{E}$ (apo $\mathrm{E})^{1}$ is one of at least 10 specific lipid binding apolipoproteins associated with the human plasma lipoproteins. The best evidence for a functional role for this apolipoprotein is provided by studies of type III hyperlipoproteinemia (dyșbetalipoproteinemia) which is associated with specific amino acid substitutions in the apo E sequence (1). This abnormal structure results in marked reduction of the affinity of apo $E$ for its receptors on liver cell membranes (2).

Studies using conventional means of lipoprotein separation have concluded that apo $E$ exists as a component of all lipoprotein classes and in a nonlipoprotein form $(3,4)$. However, Blum et al. showed that this nonlipoprotein form was an artifact of methodology and that when lipoproteins were separated by gel filtration, apo E was associated entirely with lipoproteins (5). We have recently extended this observation in studies that used $4 \%$ agarose chromatography and have shown that in normolipidemic subjects, apo $\mathrm{E}$ is distributed among at least three distinct lipoprotein subclasses (6). One of these is a subclass of chylomicrons and/or very low density lipoproteins (VLDL) (fraction I), but the other two (fractions II and III) are distinct in size from the major cholesterolcarrying lipoproteins, low density lipoproteins (LDL $)$ and high density lipoproteins (HDL). Fraction II is intermediate in size between VLDL and LDL and, as previously shown (6), comprises intermediate density lipoproteins (IDL) as well as small VLDL and large LDL (6). This identification of discrete subclasses raises questions as to their metabolic interdependence, of their relation to the major lipoprotein classes, and ultimately, of their role in the regulation of lipoprotein flux. Apo $\mathrm{E}$ is known to maintain a dynamic relationship between lipoproteins in vivo, but it is not known whether the association of apo $\mathrm{E}$ is metabolically important to each of these lipoproteins.

A reciprocal relationship exists between the apo E content in triglyceride rich lipoproteins and that in HDL. Recently, Blum documented a redistribution of apo E between VLDL and HDL subfractions when triglyceride rich lipoprotein flux was perturbed by heparin administration or fat feeding (7). Heparin administration is known to release into the circulation two enzymes normally bound to endothelial surfaces and

1. Abbreviations used in this paper: apo AI, B, CII, CIII, and E, apolipoproteins AI, B, CII, CIII, and E, respectively; HTGL, hepatic triglyceride lipase; LPL, lipoprotein lipase. 
thereby to accelerate triglyceride rich lipoprotein catabolism. These enzymes are lipoprotein lipase (LPL) and hepatic triglyceride lipase (HTGL). In vitro (8) and in situ (9) studies documenting a shift of apo E to an HDL-sized particle when VLDL or chylomicrons were exposed to LPL suggested that LPL is at least one effector of this apo $E$ distribution in postheparin plasma. No studies, however, have focused on the role that HTGL might play in apo $\mathrm{E}$ metabolism. It is in general agreed that the primary function of LPL is to initiate the hydrolysis of chylomicron and VLDL triglyceride. It has been suggested that HTGL may convert the products of LPL hydrolysis (small VLDL and IDL) into $\operatorname{LDL}(10,11)$. The metabolic role of HTGL, however, has not been fully defined. In vitro, it has been shown that HTGL hydrolyzes the triglyceride of remnant chylomicrons and VLDL more readily than that of the native lipoproteins $(11-13)$. In humans, the conversion of IDL to LDL has been shown to occur across the splanchnic bed (14), an observation that implicates a hepatic enzyme in this conversion. When HTGL was specifically inhibited in vivo by intravenous infusion of antibody into rats, a rise in plasma triglyceride was observed $(15,16)$. In similar studies in monkeys, VLDL clearance and its conversion to IDL and to LDL was impeded (17). Documentation of low HTGL levels in uremia (18), hypothyroidism, (19) and chronic liver disease (20) concomitant with triglyceride elevations and remnant lipoprotein accumulation (18-21) lend additional support to the idea of a role for HTGL in the remodeling of triglyceride rich lipoproteins, particularly at the stage of IDL catabolism. Further evidence for this concept has been provided by the recent description of two brothers with HTGL deficiency (22). The associated lipoprotein abnormality is characterized by an accumulation of intermediate-sized lipoproteins and an abnormal, triglyceride rich LDL and HDL.

To evaluate the possible role of HTGL and, separately, of LPL in the distribution of apo E among the several lipoproteins, subjects with a primary deficiency in each of these enzymes have been studied.

\section{Methods}

Biogel A-15M (200-400 mesh) was purchased from Bio-Rad Laboratories (Richmond, CA) and Trasylol (aprotinin) was supplied by Mobay Chemical Corp. (New York). Reagent kits for cholesterol and triglyceride analysis were obtained from Abbott Laboratories (North Chicago, IL) and Calbiochem-Behring Corp., American Hoechst Corp. (La Jolla, CA), respectively. Heparin $(5,000 \mathrm{IU} / \mathrm{ml})$ was purchased from Riker Laboratories, Inc. (Nothridge, CA). 5,5' Dithiobis 2 nitro benzoic acid was obtained from Sigma Chemical Co. (St. Louis, MO). All other reagents were obtained from Fisher Scientific Co. (Fairlawn, NJ).

Blood sampling. All blood samples were drawn from the antecubital vein after a 12-14 hour fast and were collected into tubes containing EDTA $(1 \mathrm{mg} / \mathrm{ml})$. Postheparin blood was obtained $15 \mathrm{~min}$ after a bolus intravenous injection of $60 \mathrm{IU} / \mathrm{kg}$ of heparin. Pre- and postheparin plasma were then separated immediately by centrifugation at 2,500 rpm for $20 \mathrm{~min}$ at $4^{\circ} \mathrm{C}$. Aliquots were kept on ice before column chromatography or frozen at $-80^{\circ} \mathrm{C}$ for later analysis of postheparin lipolytic activity. In one study, postheparin blood was obtained 15, 30, and $60 \mathrm{~min}$ after heparin injection in order to evaluate the time course of the heparin effect.

Column chromatography. Plasma lipoproteins were separated from whole plasma on $4 \%$ agarose (Biogel A-15M, 200-400 mesh) columns as previously described (6). In brief, $3-5 \mathrm{ml}$ of fresh EDTA plasma was applied to a $2.5 \times 100 \mathrm{~cm}$ column at $4^{\circ} \mathrm{C}$, equilibrated with sodium barbital buffer, $\mathrm{pH} 7$, containing $\mathrm{NaCl}(0.15 \mathrm{M})$, EDTA $(0.01 \%)$, sodium azide $(0.02 \%)$, and Trasylol $500 \mathrm{kIU} / \mathrm{ml}$. Plasma from several subjects $(4,7$, and 9) was shipped on ice via overnight courier from other laboratories; 5,5' dithiobis 2 nitro benzoic acid $(1.4 \mathrm{mM})$ was added to all shipped samples according to a current protocol in order to inhibit lecithin/cholesterol acyltransferase activity. This proved to be unnecessary in controlled experiments comparing elution profiles in normal subjects (6) and was not used for subsequent studies done locally. Lipoproteins were eluted at $20 \mathrm{ml} / \mathrm{h}$ in fractions of $\sim 10 \mathrm{ml}$. The exact volumes of the fractions were determined gravimetrically. Pre- and postheparin plasma samples were always chromatographed sequentially on the same column, and the postheparin sample was always applied first.

Since three different $4 \%$ columns were used at different times for the separate experiments, each was standardized to allow comparison of lipoprotein elution volumes. This standardization involved the chromatography of a normal plasma sample with the monitoring of cholesterol, triglyceride, and apolipoproteins B and AI (apo B and apo AI, respectively). The void volume was determined from samples containing chylomicrons. The difference in void volume and elution volume of HDL (determined by cholesterol and apo AI elution profiles) was assigned a relative elution volume of 1.0. In a similar manner, the elution volumes of the LDL and the nadir of the apo $\mathrm{E}$ distributions for fractions I, II, and III were determined by the use of normal plasma. The elution volumes for the three columns used for all experiments reported in this article are given in the legend to Table III and are specified in the appropriate figures. Thus, the range of volumes containing apo E, fractions I, II, and III were precisely defined and held invariant for each column.

Postheparin lipolytic activity. Postheparin lipolytic activities for LPL and HTGL were measured after differential inhibition of the two enzymes (23).

Lipid and apolipoprotein analysis. Cholesterol and triglyceride concentrations of plasma and column fractions were analyzed on the ABA 100 Autoanalyzer (Abbott Laboratories) by enzymatic methods $(24,25)$. HDL cholesterol was determined on the supernatant fraction of plasma after the precipitation of apo B-containing lipoproteins by dextran sulfate and $\mathrm{MgCl}_{2}(26)$.

Apolipoprotein quantitation. Apo E, B, and AI, and apolipoproteins CII and CIII (apo CII and CIII, respectively) were measured by use of specific radioimmunoassays (RIAs). Details of these RIAs have been reported elsewhere for apo E, B, AI (6), and CIII (27). The procedure for the apo CII RIA is analogous to that detailed for apo CIII (27) in terms of the buffer components and mode of separation of bound from free antigen, but it has not been presented in detail previously. A buffer of $0.1 \mathrm{M}$ borate, $0.01 \%$ Triton X-100, $0.1 \%$ ovalbumin, and Trasylol $(500 \mathrm{kIU} / \mathrm{ml}) \mathrm{pH} 8.5$ was used throughout. Bound antigen was separated from free by the addition of $20 \mu \mathrm{l}$ of goat anti-rabbit serum $48 \mathrm{~h}$ after the primary antibody incubation followed by the addition, $24 \mathrm{~h}$ later, of polyethylene glycol 6,000 to give a final concentration of $10 \%$. The apo CII used as tracer, standard, and for immunization was purified from VLDL by delipidation, gel filtration, and ion exchange chromatography as described for apo CIII. The apo CIII which inevitably contaminated the apo CII after ion exchange chromatography was then removed by immunoaffinity chromatography on anti-apo CIII IgG Sepharose CL-4B (27).

This RIA has a working range of $0.10-10.0 \mathrm{ng}$ apo $\mathrm{CII}$ and has been validated by the same criteria previously applied to the RIAs for apo AI, B, E (6), and CIII (27). Specifically, when five normolipidemic and five hypertriglyceridemic sera were assayed before and after delipidation with acetone/isopropanol (28), the values obtained were not significantly different after paired $t$ test analysis (mean difference \pm standard deviation of intact - delipidated, $3.04 \pm 7.15 \mu \mathrm{g} / \mathrm{ml}$ ). The measured recovery of standard amounts of purified apo CII after addition to either normal or hypertriglyceridemic sera was $92 \pm 5 \%$ of that expected $(n=12)$. The interassay coefficient of variation was assessed by assay of five sera replicated six times in a single assay. The coefficients of variation were $5.4,5.5,8.1,5.1$, and $6.8 \%$, respectively. When four quality control sera were assayed (in duplicate) in 11 sequential assays over $10 \mathrm{mo}$, the coefficient of interassay variation 
ranged from 14.35 to $22.8 \%$, with an average of $19.8 \%$. Finally, in order to verify that measurements of serum and lipoprotein apo CII levels were independent of dilution, an HDL sample was assayed in 10 different dilutions and the slope, after log-logit transformation of the data, was compared with that of the purified apo CII standard. The slope of the HDL dilutions was -0.925 , compared with -0.928 for the purified apo CII standard.

Isoelectric focusing. To determine the apo E phenotype, analytical isoelectric focusing was carried out on VLDL samples prepared by ultracentrifugation at a density of $1.006 \mathrm{~g} / \mathrm{ml}$ for $16 \mathrm{~h}$ at $39,000 \mathrm{rpm}$ in a 40.3 rotor in an ultracentrifuge (L5-65; Beckman Instruments Inc., Fullerton, CA). Delipidation was done with 20 vol of acetone followed by $20 \mathrm{vol}$ of isopropanol (28). The apolipoproteins of VLDL were then solubilized in $50 \mathrm{mM}$ ammonium bicarbonate containing 4 $\mathrm{mM}$ sodium dodecyl sulfate and focused on $7.5 \%$ polyacrylamide gels as described by Weidman (29).

\section{Results}

Clinical characteristics. The clinical characteristics of the subjects studied are summarized in Tables I and II. These include lipoprotein phenotype, age, lipid, and apolipoprotein levels. The first three subjects were classified as normolipidemic based upon comparison of their lipid and lipoprotein values to the Lipid Research Clinic values for age (30). Their apolipoprotein levels were also normal as compared to apolipoprotein norms determined in this laboratory (6). Subjects 4, 5, and 6 were children with LPL deficiency, and patient 7 was a young adult diagnosed in childhood as having LPL deficiency. The fasting plasma of each of these subjects was milky with a floating chylomicron layer. The triglyceride levels were high and the cholesterol values were within normal limits. LPL in these subjects was below accurate detection by the assay system (Table I). Apo CII was actually higher than normal. Subjects 8 and 9 were recently reported to have HTGL deficiency (22). Clinical histories and lipoprotein profiles have been given in detail elsewhere (22). The proband (subject 9) developed diabetes mellitus and was on insulin therapy after the initial
Table II. Apolipoprotein Levels in Pre- and Postheparin Plasma

\begin{tabular}{|c|c|c|c|c|c|c|c|c|}
\hline \multirow[b]{2}{*}{ No. } & \multicolumn{2}{|l|}{ Apo B } & \multicolumn{2}{|l|}{ Apo AI } & \multicolumn{2}{|c|}{ Apo CIII } & \multicolumn{2}{|l|}{ Apo E } \\
\hline & Pre & Post & Pre & Post & Pre & Post & Pre & Post \\
\hline & $\mathrm{mg} / \mathrm{ml}$ & $m g / m l$ & $m g / m l$ & $\mathrm{mg} / \mathrm{ml}$ & $\mu g / m l$ & $\mu g / m l$ & $\mu g / m l$ & $\mu g / m l$ \\
\hline \multicolumn{9}{|c|}{ Normolipidemic } \\
\hline 1 & 0.746 & 0.830 & 1.34 & 1.338 & 148.0 & 151.9 & 48.5 & 49.5 \\
\hline 2 & 1.89 & 1.19 & 1.22 & 1.02 & 197.4 & 219.4 & 62.0 & 63.6 \\
\hline 3 & 0.626 & 0.628 & 1.45 & 1.15 & 135.7 & 131.7 & 80.7 & 84.7 \\
\hline \multicolumn{9}{|c|}{ LPL-deficient } \\
\hline 4 & 0.375 & 0.312 & 0.44 & 0.79 & 137.8 & 174.7 & 64.9 & 51.5 \\
\hline 5 & 0.467 & ND & 0.71 & ND & 312.1 & 305.6 & 85.0 & 80.2 \\
\hline 6 & 0.402 & 0.381 & 0.78 & 0.75 & 174.3 & 178.6 & 78.5 & 76.0 \\
\hline 7 & ND & ND & ND & ND & 209.4 & 145.8 & 103.6 & 99.2 \\
\hline \multicolumn{9}{|c|}{ HTGL-deficient } \\
\hline 8 & 1.904 & 1.91 & 2.98 & 2.75 & 404.8 & 332.5 & 122.2 & 116.4 \\
\hline 9 & 2.814 & 3.00 & 1.82 & 1.75 & 530.5 & 497.0 & 208.4 & 223.44 \\
\hline \multicolumn{9}{|c|}{ Type V } \\
\hline 10 & 0.780 & 0.801 & 1.19 & 1.034 & 700.0 & 821.2 & 127.2 & 118.0 \\
\hline 11 & 1.315 & 1.71 & 1.06 & 1.05 & 981.8 & 1012 & 489.1 & 515.48 \\
\hline
\end{tabular}

Pre, preheparin. Post, postheparin. ND, not determined.

report and before the present study. His brother (subject 8) was not diabetic and was less hyperlipoproteinemic. Subjects 10 and 11 demonstrated the classical lipid profile of type $\mathrm{V}$ hyperlipoproteinemia, with elevated chylomicron and VLDL triglyceride and reduced LDL and HDL levels. Patient 10 was a mild diabetic treated by diet alone. Patient 11 was a young woman with diabetes mellitus on oral hypoglycemic therapy.

\section{Lipoprotein and apolipoprotein profiles}

Normal subjects. Separation of the major lipoprotein classes by $4 \%$ agarose chromatography is illustrated in Fig. $1 a$ by the use of plasma from one normolipidemic subject. All three

Table I. Clinical Characteristics of Study Subjects

\begin{tabular}{|c|c|c|c|c|c|c|c|c|}
\hline No. & Sex & Age & Cholesterol & TG & HDL-C & HTGL & LPL & Apo $\mathrm{E}$ isoforms \\
\hline & & & $m g / d l$ & $m g / d l$ & $m g / d l$ & $\mu \mathrm{mol} F A / m l$ per $h$ & $\mu \mathrm{mol} F A / m l$ per $h$ & \\
\hline \multicolumn{9}{|c|}{ Normolipidemic } \\
\hline 1 & $\mathbf{M}$ & 33 & 164 & 114 & 35 & 23.4 & 10.7 & E2/E3 \\
\hline 2 & $\mathbf{M}$ & 44 & 196 & 183 & 31 & 45.1 & 10.8 & E3/E4 \\
\hline 3 & $\mathbf{F}$ & 50 & 181 & 81 & 56 & 48.5 & 12.3 & E3/E4 \\
\hline \multicolumn{9}{|c|}{ LPL-deficient } \\
\hline 4 & $F$ & 3 & 83 & 915 & 11 & 46.8 & 1.8 & ND \\
\hline 5 & $\mathbf{F}$ & 4 & 125 & 860 & 12 & 74.8 & 0 & E3/E4 \\
\hline 6 & $\mathbf{M}$ & 2.5 & 124 & 630 & 12 & 51.8 & 0 & E3/E4 \\
\hline 7 & $\mathbf{F}$ & 21 & 145 & 910 & ND & 37.9 & 0.6 & ND \\
\hline \multicolumn{9}{|c|}{ HTGL-deficient } \\
\hline 8 & $\mathbf{M}$ & 49 & 330 & 466 & 59 & 3.0 & 16.3 & E3/E4 \\
\hline 9 & $\mathbf{M}$ & 48 & 375 & 1,128 & 35 & 2.0 & 14.3 & E3/E4 \\
\hline \multicolumn{9}{|c|}{ Type V } \\
\hline 10 & $\mathbf{M}$ & 57 & 392 & 1,738 & 15 & 39.5 & 14.3 & $\mathrm{E} 3 / \mathrm{E} 4$ \\
\hline 11 & $\mathrm{~F}$ & 28 & 626 & 4,179 & 14 & 41.9 & 9.6 & E4/E4 \\
\hline
\end{tabular}

ND, not determined. TG, triglyceride. 


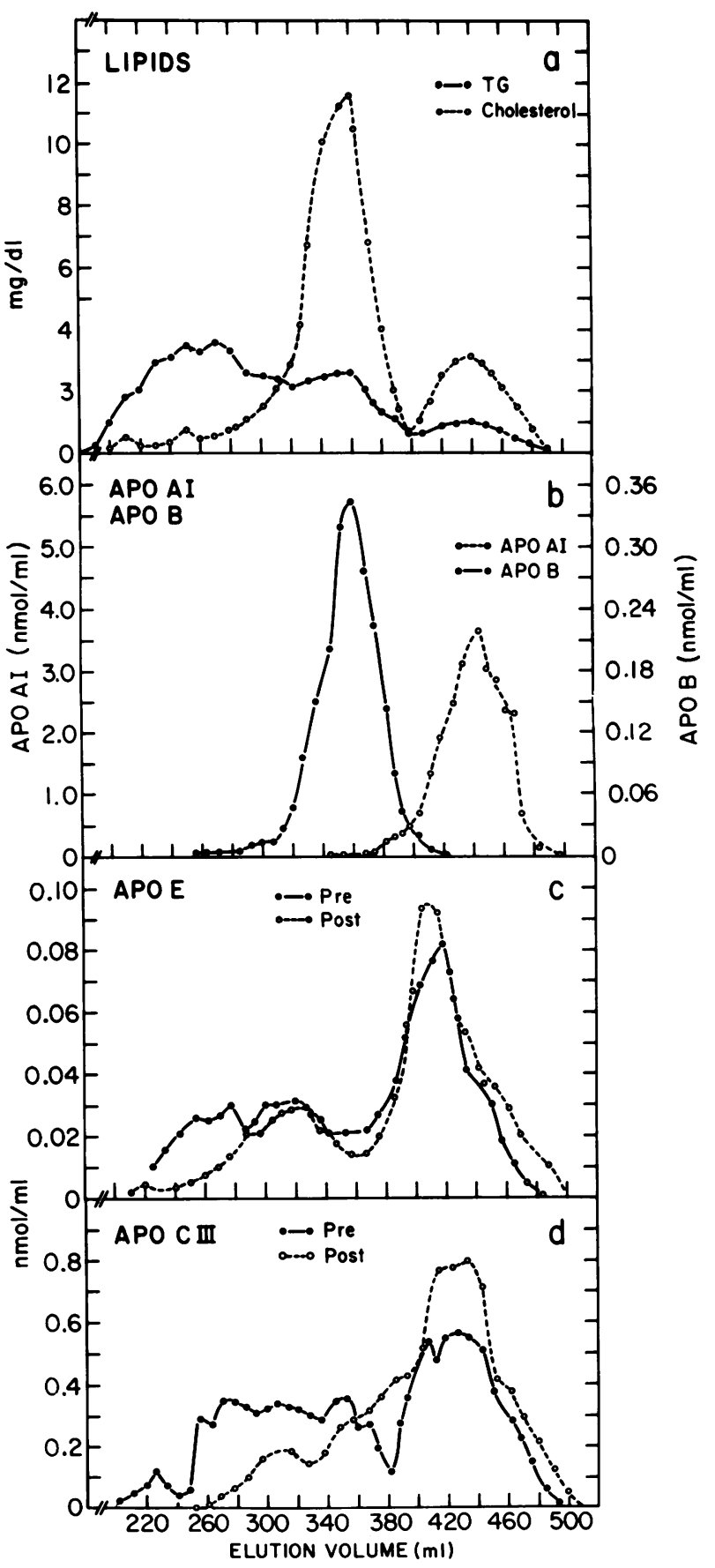

Figure 1. Lipid and apolipoprotein profiles of a normolipidemic subject (subject 1 , Table I) after $4 \%$ agarose chromatography of whole plasma. (a) Triglyceride (TG) and cholesterol profiles before heparin administration are shown. (b) Apo B and AI peaks confirm the positions of LDL and HDL in preheparin plasma. Plasma levels and elution profiles were unchanged after heparin. $(c)$ The distribution of apo $\mathrm{E}$ among its subfractions was altered such that fraction III was enriched at the expense of fraction I. Fraction I is defined as all apo E in elute from 200 to $280 \mathrm{ml}$. Fraction II is that from 280 to $340 \mathrm{ml}$ and fraction III is that present in the elute from 380 to 480 $\mathrm{ml}$. The plasma level of apo $\mathrm{E}$ was unchanged in pre- and postheparin plasma (48.5 vs. $49.5 \mu \mathrm{g} / \mathrm{ml}$ ). (d) Plasma levels of apo CIII were constant ( 148.0 vs. $151.9 \mu \mathrm{g} / \mathrm{ml})$ pre- and postheparin, but the mass of apo CIII declined in VLDL and increased HDL. fasting normolipidemic subjects demonstrated a major broad peak of triglyceride, corresponding to the VLDL. The dominant cholesterol peak of these and all subjects corresponded to LDL and the smaller fraction represented the HDL as demonstrated by coelution with apo $\mathrm{B}$ and $\mathrm{AI}$, respectively (Fig. $1 b$ ).

Unlike the profiles of apo B and AI, which were coincident with the major lipid fractions, both apo $\mathrm{E}$ and CIII were found in complex elution profiles. In normal fasting subjects, apo $\mathrm{E}$ was associated with lipoprotein particles of three distinct sizes as described in detail elsewhere (6) and exemplified by two subjects in Figs. $1 c$ and $2 c$. In general, these apo $\mathrm{E}$ enriched subclasses represent lipoproteins the size of VLDL (designated as fraction I), and two subclasses which are distinct from the major cholesterol carrying lipoproteins. Apo E fraction II elutes as a particle slightly larger than LDL but smaller than VLDL (Fig. $1 c$ ). In the subject shown in Fig. 2, fraction II is apparent as a shoulder on the larger VLDL fraction I. Fraction III is primarily a subclass of HDL but extends into the LDL density range $(d, 1.019$ to 1.063$)(6)$ and is intermediate in size between HDL and LDL (Figs. $1 c$ and $2 c$ ). In a previous study we showed that the distribution of apo $E$ in a small group of normolipidemic subjects was quite variable, but on the average, 10, 20, and $70 \%$ were found in fractions I, II, and III, respectively (6).

RIA analysis of apo CIII of fractions obtained by $4 \%$ agarose chromatography of whole plasma revealed an equally complex distribution of apo CIII, but one that was different from that of apo E. In the normal, fasting subject shown in Fig. $1 d$, apo CIII had a broad distribution among lipoproteins the size of VLDL and IDL. In another, shown in Fig. $2 d$, apo CIII was more discretely associated with subclasses of VLDL and IDL. Another major fraction of apo CIII eluted with particles slightly larger than those HDL particles containing the bulk of apo AI and cholesterol but smaller than the particles containing apo E (i.e., fraction III). Nearly identical distributions were observed for apo CII (data not shown). In fact, in all studies cited below, apo CIII and CII behaved almost identically.

After heparin administration, no changes in the total mass or size distribution of cholesterol or apo B or AI were noted. 15 min after heparin, the plasma triglyceride concentration had fallen (Table III), whereas the levels of apo E and CIII were unchanged in normal subjects (Table II). However, the distribution of both of these apolipoproteins was altered, with an increase in apo $E$ in the HDL-sized lipoproteins and a concomitant reduction in that of VLDL-sized particles (Table III). Furthermore, this change in distribution was associated with an apparent increase in the size of the particles containing apo $\mathrm{E}$ in $\mathrm{HDL}$ (fraction III), as evidenced by reduced elution volume (Figs. $1 c$ and $2 c$ ). In general, the masses of both apo $\mathrm{E}$ and $\mathrm{CIII}$ in intermediate-sized lipoproteins were changed minimally (Table III). These changes in the lipoprotein association of apo $\mathrm{E}$ and CIII after heparin are shown in detail for two subjects in Figs. 1, $c$ and $d$, and 2,c and $d$. They were summarized for all three normal subjects in Fig. 3 and Table III.

Plasma was obtained for chromatography from the same normolipidemic subject depicted in Fig. 1 after several intervals following heparin administration. These data are summarized in Fig. 4. No changes in the total plasma levels of apo E or 


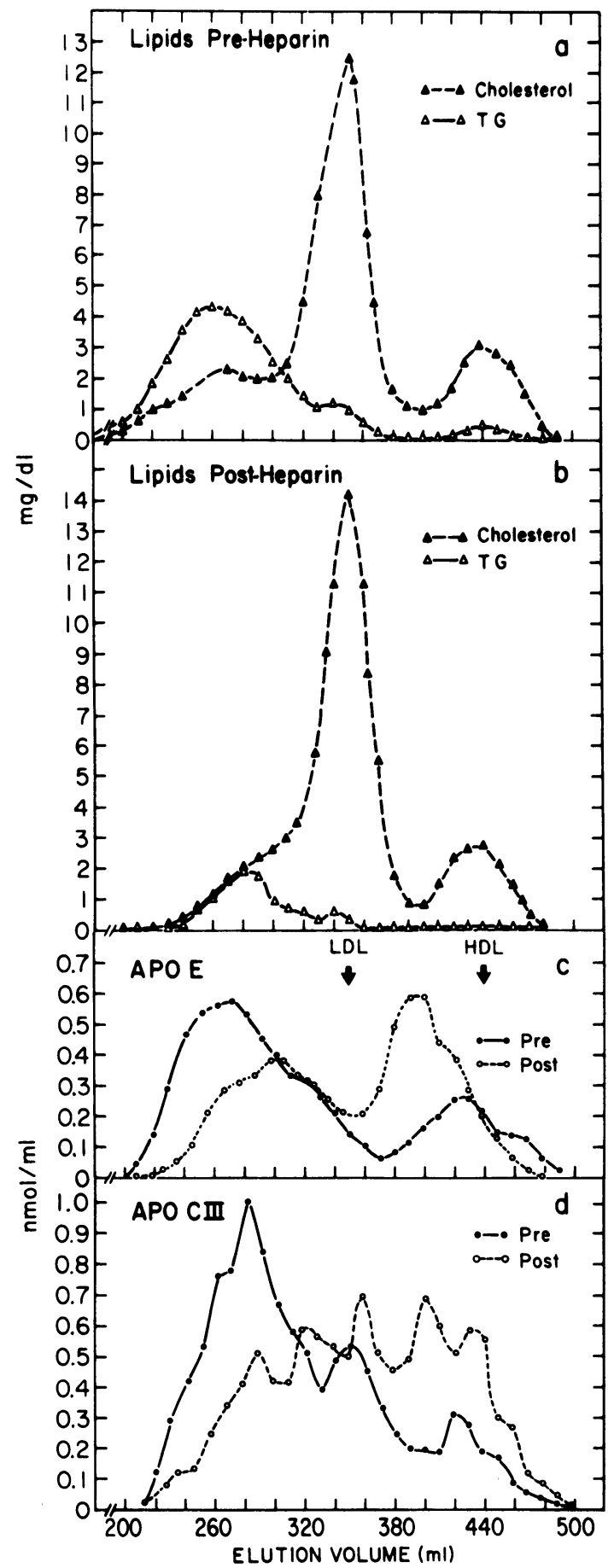

Figure 2. Chromatography on $4 \%$ agarose column of plasma from subject 2 with normal lipid levels. The column used was the same as in Fig. 1. (a) Cholesterol and triglyceride (TG) concentration in each faction before heparin injection. (b) Cholesterol and triglyceride concentration in each faction after each heparin injection. (c) Apo E concentration in each faction before and after heparin injection. $(d)$ Apo CIII concentration in each faction before and after heparin injection. Constant plasma levels of apo $E$ were maintained (62.0 vs. $63.3 \mu \mathrm{g} / \mathrm{ml}$ ), but the mass of apo $\mathrm{E}$ in fraction I was decreased and that in fraction III was increased after heparin administration. Plasma apo CIII levels were also unchanged in pre- and postheparin plasma (107.4 vs. $109.7 \mu \mathrm{g} / \mathrm{ml})$ and showed similar shifts from VLDL- to HDL-sized lipoproteins. Arrows mark the position of LDL and HDL, which were unchanged by heparin.
Table III. Changes in the Content of TG and of Apo $E$ in Fractions I, II, and III Before and After Heparin

\begin{tabular}{|c|c|c|c|c|c|c|c|c|}
\hline \multirow[b]{3}{*}{ No. } & \multicolumn{6}{|c|}{ Apo $\mathrm{E}(\mu g / m l)$} & \multirow{2}{*}{\multicolumn{2}{|c|}{$\begin{array}{l}\text { VLDL-TG } \\
(m g / m l)\end{array}$}} \\
\hline & \multicolumn{2}{|c|}{ Fraction I } & \multicolumn{2}{|c|}{ Fraction II } & \multicolumn{2}{|c|}{ Fraction III } & & \\
\hline & Pre & Post & Pre & Post & Pre & Post & Pre & Post \\
\hline \multicolumn{9}{|c|}{ Normolipidemic } \\
\hline 1 & 9.1 & 5.0 & 10.4 & 9.9 & 19.3 & 34.6 & 0.49 & 0.08 \\
\hline 2 & 33.5 & 10.5 & 12.6 & 11.4 & 18.3 & 33.3 & 1.36 & 0.48 \\
\hline 3 & 3.1 & 0.6 & 9.0 & 6.1 & 68.6 & 78.1 & 0.43 & 0.06 \\
\hline \multicolumn{9}{|c|}{ LPL-deficient } \\
\hline 4 & 52.7 & 22.1 & 3.2 & 3.0 & 3.9 & 25.9 & 8.56 & 6.28 \\
\hline 5 & 65.5 & 53.9 & 3.6 & 2.9 & 15.6 & 23.7 & 6.20 & 4.40 \\
\hline 6 & 43.2 & 26.0 & 2.5 & 1.7 & 33.4 & 48.2 & 3.96 & 3.69 \\
\hline 7 & 72.7 & 24.6 & 8.7 & 4.4 & 22.8 & 70.5 & 6.5 & 5.35 \\
\hline \multicolumn{9}{|c|}{ HTGL-deficient } \\
\hline 8 & 29.6 & 7.0 & 51.4 & 60.4 & 31.7 & 49.5 & 0.61 & 0.03 \\
\hline 9 & 86.2 & 69.5 & 101.3 & 119.5 & 15.1 & 22.2 & 3.92 & 2.06 \\
\hline \multicolumn{9}{|c|}{ Type V } \\
\hline 10 & 97.8 & 58.4 & 15.2 & 6.4 & 9.3 & 53.2 & 12.50 & 10.94 \\
\hline 11 & 430.3 & 264.2 & 15.2 & 17.2 & 31.8 & 272.7 & 25.02 & 23.20 \\
\hline
\end{tabular}

Pre, preheparin. Post, postheparin. The apo E found in Fractions I, II, and III from plasma obtained before and $15 \mathrm{~min}$ after intravenous heparin injection is given for all subjects in the present study. The change in triglyceride (TG) content in fraction I after heparin injection is also shown. Values have been divided by the volume of plasma applied to the column. Fraction I is the eluate from the void volume to the minimum of the apo $\mathrm{E}$ concentration in the small VLDL size range as defined by chromatography of normal plasma. A relative elution volume (RE) (see below) of 0.33 was found in each column to this minimum. Fraction II is the apo $\mathrm{E}$ in the eluate from RE of 0.33 (the end of Fraction I) to the second minimum in the apo $\mathrm{E}$ distribution. This occurred near the rising portion of the apo $B$ curve in large LDL and had an RE of 0.62 . Fraction III is the apo $E$ eluate defined by the chromatography of normal plasma and includes the distribution of apo $E$ in particles smaller than LDL. These range in RE from 0.75 to 1.20 . The volumes corresponding to these RE were defined for each column. RE was determined by the equation: $R E=\left(V_{0}-V_{x}\right) /\left(V_{0}-V_{H D L}\right)$, where $V_{0}$ is the void volume of column, $V_{x}$ is the elution volume of specified interest, and $V_{H D L}$ is the elution volume of normal HDL apo AI.

CIII were seen at 15 or $30 \mathrm{~min}$. At $60 \mathrm{~min}$, however, the plasma apo E level had decreased by $36 \%$. Plasma apo CIII remained constant. With time, both apo $\mathrm{E}$ and CIII demonstrated a reduction in the proportion associated with VLDL and an increase in that associated with HDL. Again, little change was seen in the proportion of either apolipoprotein in intermediate-sized lipoproteins. This redistribution was rapid and continuous between 0 and $30 \mathrm{~min}$ after heparin and was completed with little further change at $60 \mathrm{~min}$. Plasma triglyceride levels showed a similar time course, decreasing from 114 to $55 \mathrm{mg} / \mathrm{dl}$ between 0 and $30 \mathrm{~min}$ but changing minimally between 30 and $60 \mathrm{~min}$.

To verify that no further shifts in apolipoprotein distribution occurred in vitro, the samples were kept at $0^{\circ} \mathrm{C}$ (but not frozen) before chromatography, the 30 -min sample from this 


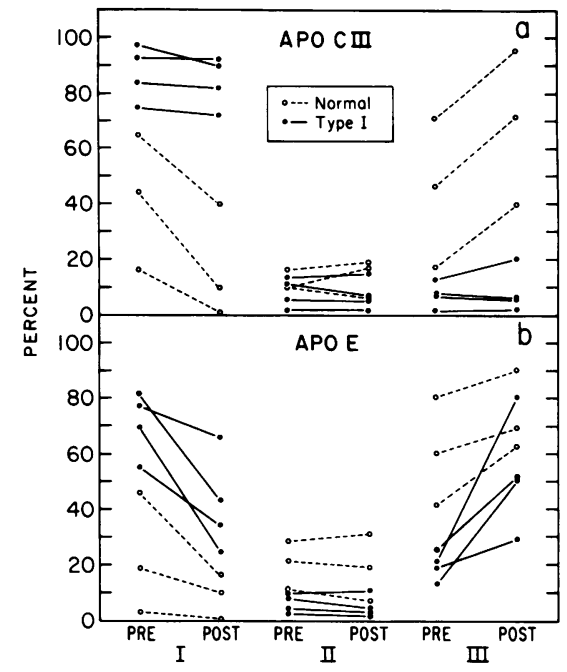

Figure 3. Changes in the proportion of apo E and apo CIII associated with VLDL (fraction I), intermediate-sized lipoproteins (fraction II), and HDL-sized lipoproteins (fraction III) before and after heparin administration in normal and LPL-deficient (-•-) subjects. All subjects, regardless of LPL status, demonstrated reductions in apo E in fraction I, with parallel increases in fraction III. In contrast, LPLdeficient subjects did not show the shift of apo CIII from VLDL to HDL seen in normal subjects.

study was divided into two parts, and one portion was chromatographed immediately and the second $48 \mathrm{~h}$ later. The apo E distribution was identical in the two samples $(0.2$ vs. $0.1 \%$ in VLDL, 24.9 vs. $24.4 \%$ in fraction II, and 74.8 vs. $75.6 \%$ in fraction III). The possible role of heparin itself in altering the apo $\mathrm{E}$ distribution was ruled out by two in vitro studies in which plasma was chromatographed after $15 \mathrm{~min}$ of incubation $\left(37^{\circ} \mathrm{C}\right)$ either with or without heparin $(2 \mathrm{U} / \mathrm{ml})$. The distribution of apo $\mathrm{E}$ was unchanged by the addition of heparin in vitro.

LPL-deficient subjects. Type I hyperlipoproteinemic subjects

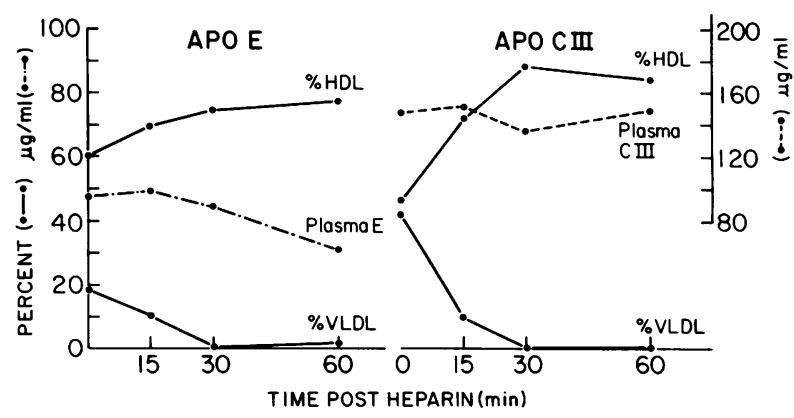

Figure 4. Changes in plasma apo $\mathrm{E}$ and $\mathrm{CIII}$ levels and their distribution among the lipoproteins (VLDL and HDL) after heparin administration. The lipoproteins were separated by $4 \%$ agarose column chromatography that used plasma from a normolipidemic subject (subject 1) obtained at the times indicated. Apo E levels were constant from 0 to $15 \mathrm{~min}$ postheparin but were reduced at $60 \mathrm{~min}$. The proportion of apo E decreased continuously in VLDL between 0 and $30 \mathrm{~min}$, with parallel increases in the percentage in HDL. Apo CIII levels were constant between 0 and $60 \mathrm{~min}$, but a rapid redistribution of apo CIII occurred between VLDL and HDL, which was complete by $30 \mathrm{~min}$. Chromatography was performed on separate columns immediately after the plasma was separated from the cellular components. were documented as being markedly deficient in LPL activity but normal or high normal with respect to postheparin HTGL activity. In these subjects, plasma triglyceride levels were markedly elevated, whereas cholesterol levels were low (Table I). Unlike in normolipidemic subjects, there was fasting hyperlipoproteinemia and this was manifested as a void volume peak of triglyceride on $4 \%$ agarose chromatography (Fig. $5 a$ ). Plasma LDL cholesterol and apo B, and HDL cholesterol and apo AI were reduced (Tables I and II). Both plasma apo CIII and $\mathrm{E}$ levels (Table II) were significantly increased $(P<0.001)$ relative to a large group of normolipidemic adult male subjects studied previously in this laboratory (6). A control population of comparable age was not available, but one of the LPLdeficient subjects was a young adult female (subject 7), and she did not differ from the children (subjects 4-6) in her lipid or apolipoprotein profiles.

LPL-deficient subjects were also unusual in that their apo E was distributed almost entirely among two subfractions (Fig. $5 c$ ). One was a large, discrete chylomicron fraction coincident with void volume triglyceride and the other was the apo $\mathrm{E}$ subfraction of HDL size, fraction III. Relatively little apo E was seen in either VLDL or in the intermediate-sized fraction II. This was a consistent pattern seen in all four subjects.

In contrast to apo $\mathrm{E}$, by far the major portion of apo CIII was seen in lipoproteins the size of VLDL and in the chylomicron fraction (Fig. $5 d$ ). Less apo CIII was found in HDLsized lipoproteins, but little was found in intermediate-sized particles. The lipoprotein distribution of apo CII was very similar to that of apo CIII (Fig. 5, $d$ and $e$ ).

Intravenous heparin failed to induce significant triglyceride hydrolysis in LPL-deficient subjects (Table III). Despite this, apo $\mathrm{E}$ levels in the chylomicron fractions were reduced after heparin, and those in HDL were elevated in a pattern similar to that seen in normolipidemic subjects with active LPL (Fig. 5 c). As with normal subjects, the apo $\mathrm{E}$ fraction within HDL (fraction III) which increased after heparin, was larger than in the basal state, as indicated by a reduced elution volume. No increase in the amount of apo $\mathrm{E}$ in intermediate-sized lipoproteins (fraction II) was seen after heparin injection. In contrast to the heparin-induced redistribution of apo $\mathrm{E}$, the apo CIII and CII profiles of type I subjects were unchanged $15 \mathrm{~min}$ after heparin. Fig. 3 compares the pre- and postheparin apo $\mathrm{E}$ and CIII content in fractions I, II, and III in four type I subjects with those of the three normolipidemic control subjects. This emphasizes the dissociation of apo E and CIII dynamics seen in LPL-deficient subjects.

HTGL-deficient subjects. The HTGL-deficient subjects (subjects 8 and 9, Table I) were similar in that both had elevated levels of triglyceride and cholesterol in whole plasma. The LDL and HDL were triglyceride enriched as compared with the same lipoproteins from the other subjects studied (Figs. 6, $a$ and $b$, and 7, $a$ and $b$ ). In the diabetic (subject 9) triglycerides were markedly increased in small VLDL and intermediate sized particles as well as in LDL. HTGL activity was markedly deficient (5-10\% normal) in postheparin plasma, whereas LPL ativity was high normal in both. The levels of total plasma apo E and apo CIII were higher than normal to a degree that mirrored the hypertriglyceridemia in each subject (Table II). In both subjects, the major component of apo $\mathrm{E}$ was found to elute as lipoproteins of intermediate size (Figs. 6 $c$ and $7 c$ ). 


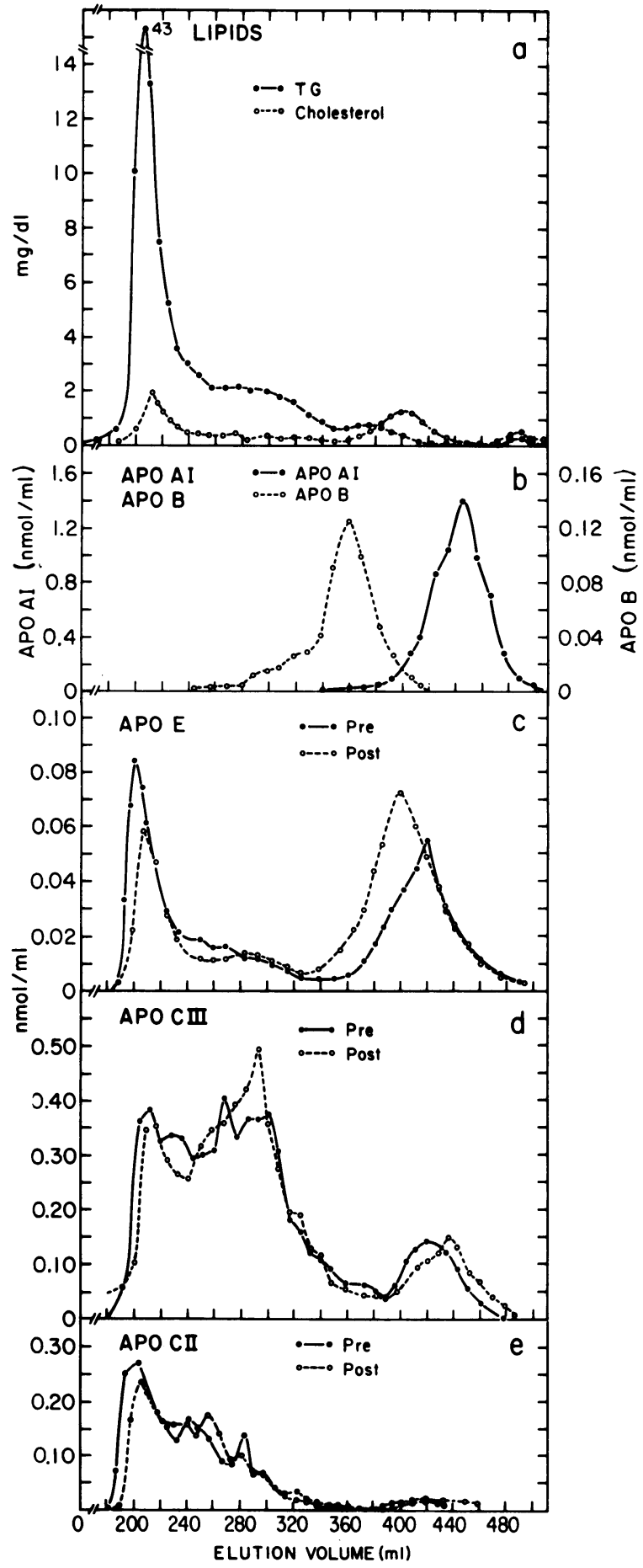

Figure 5. Lipid and apolipoprotein profiles of an LPL-deficient subject (subject 6). (a) The large void volume peak $(210 \mathrm{ml}$ elution volume) of triglyceride (TG) represents the chylomicron fraction. (b) Apo B and AI profiles mark the position of the LDL and HDL, respectively, in preheparin plasma. These were unchanged in postheparin plasma. (c) Total plasma apo E levels were similar in preand postheparin plasma ( $78.5 \mathrm{vs}$. $76.0 \mu \mathrm{g} / \mathrm{ml})$, but the lipoprotein distribution was shifted after heparin administration. apo $\mathrm{E}$ in the chylomicron/VLDL fraction I (190 to $290 \mathrm{ml})$ was reduced and that in the fraction III (380 to $480 \mathrm{ml})$ was increased. $(d)$ Total plasma apo CIII levels were essentially unchanged in pre- and postheparin plasma $(174.3$ vs. $178.6 \mu \mathrm{g} / \mathrm{ml})$, as was the distribution of the apolipoproteins among the various lipoproteins. (e) Total plasma apo $\mathrm{CII}$ levels were similar in pre- and postheparin plasma (64.4 vs. $65.6 \mu \mathrm{g} /$

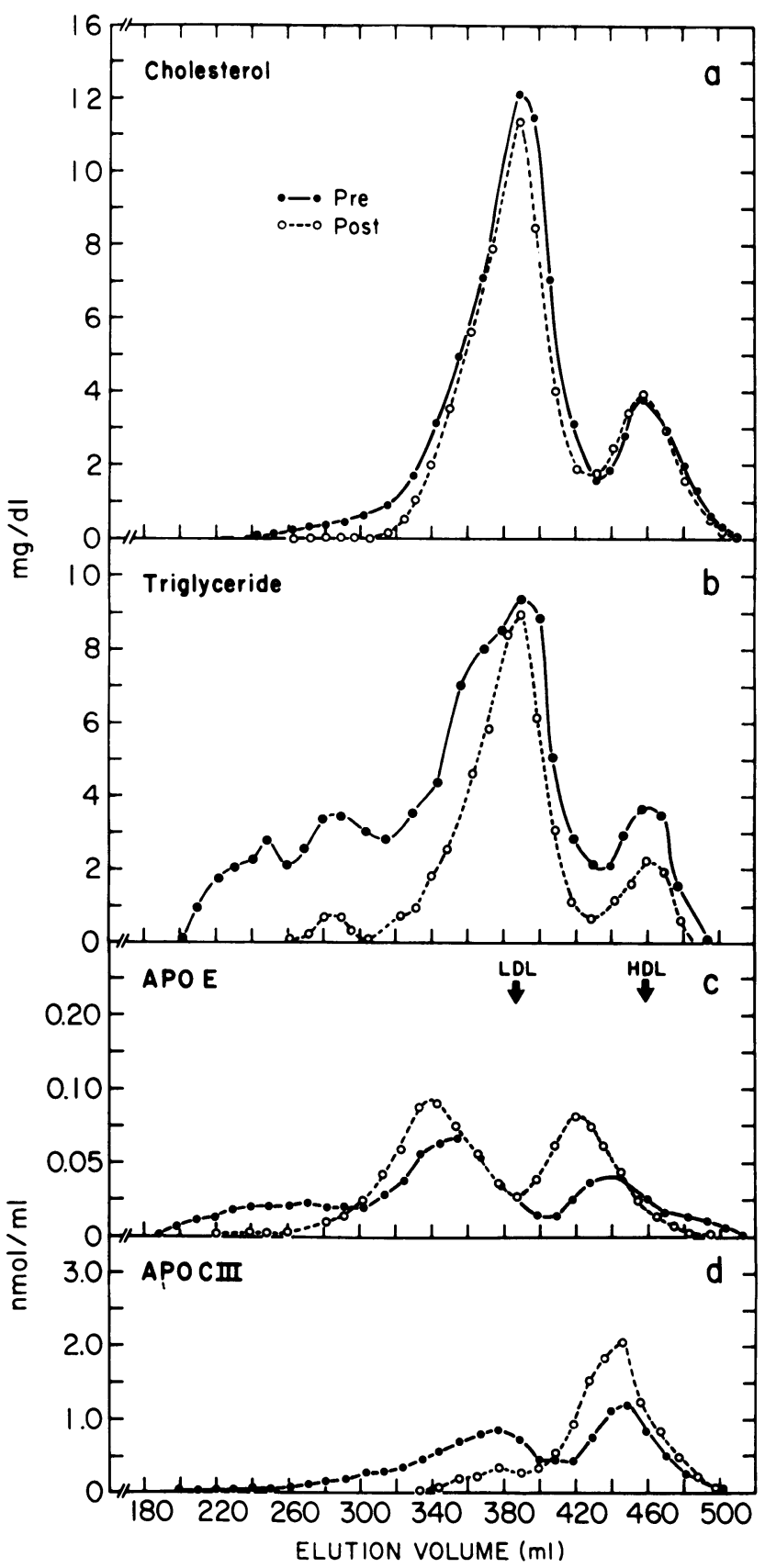

Figure 6. 4\% agarose chromatography of plasma from a subject with familial hepatic triglyceride lipase deficiency (subject 8). A comparison is shown of the lipids and apolipoproteins before and $15 \mathrm{~min}$ after intravenous administration of heparin. (a) Cholesterol levels measured in each fraction show a small decline in particles of VLDL and LDL size. (b) A marked decline in triglycerides in VLDL- and IDL-sized particles is seen. (c) Apo E in fraction I (190 to $290 \mathrm{ml})$ declined sharply, that in fraction II (290 to $360 \mathrm{ml})$ increased, and that in fraction III ( 395 to $500 \mathrm{ml}$ ) increased then decrease. (d) Apo CIII declined in fractions containing particles a size larger than HDL and increased markedly in those of HDL size.

Subject 8 was the less hyperlipoproteinemic of the two siblings with HTGL deficiency. In the base-line plasma sample, apo $\mathrm{E}$ was present in lipoproteins the size of VLDL (fraction

$\mathrm{ml}$ ) and almost all apo CII was associated with triglyceride rich lipoproteins both pre- and postheparin. 


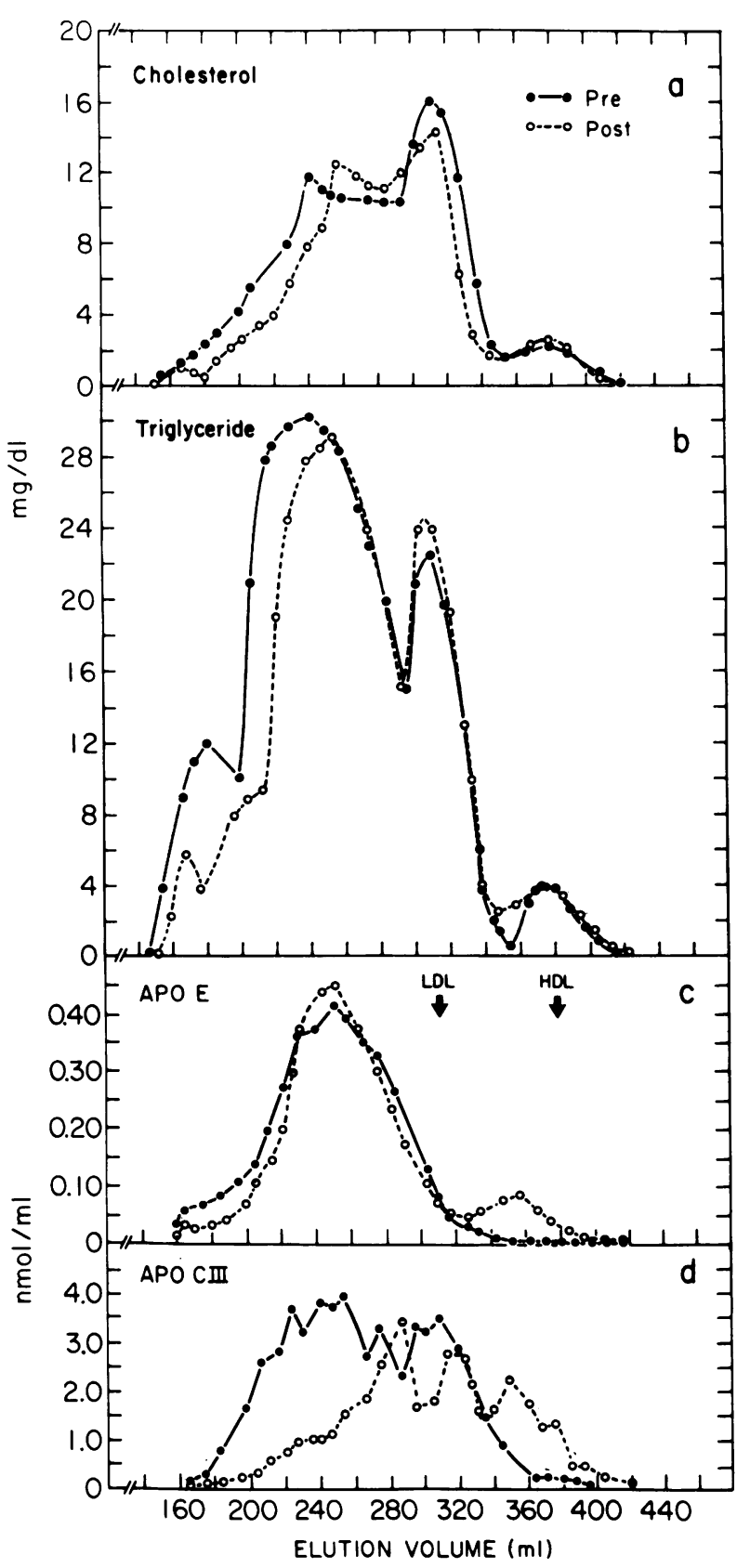

Figure 7. Column chromatography (4\% agarose) of plasma from a subject with familial HTGL deficiency (subject 9). The plasma was obtained and chromatographed exactly as that of his brother was (Fig. 6). After heparin injection, a decline in cholesterol, triglyceride, and apo $\mathrm{E}$ are noted in eluate from 160 to $235 \mathrm{ml}$ (fraction I). Apo E increased in fraction II ( 235 to $300 \mathrm{ml})$ and in fraction III (330 to $400 \mathrm{ml}$ ). Apo CIII decreased in particles larger than LDL and increased in those of HDL size.

I) and in HDL (fraction III), but the dominant distribution was in fraction II (Fig. $6 \mathrm{c}$ ). The proportion of apo $\mathrm{E}$ in fraction II was unusually large relative to that seen in normal subjects. Apo CIII was distributed among lipoproteins the size of IDL and HDL, with the major proportion in HDL (Fig. 6 d). After heparin administration, the triglyceride content of the VLDL sized particles fell markedly, from 0.61 to 0.03 $\mathrm{mg} / \mathrm{ml}$ (Table III). Both apo $\mathrm{E}$ and CIII in VLDL virtually disappeared after heparin administration. apo $\mathrm{E}$ increased in both fractions II and III after heparin administration (Fig. $6 \mathrm{c}$ ). The increase in size of the fraction III particles was similar to that seen in all other subjects studied. In contrast, the increase of apoE content in fraction II in these two patients was not observed in normal or LPL-deficient subjects. The apo CIII content of the intermediate-sized lipoproteins decreased and a concomitant, marked rise in the concentration of this apolipoprotein was observed in HDL-sized lipoproteins, as seen in normal subjects (Fig. $6 d$ ).

Subject 9 had severe hypertriglyceridemia, with total plasma triglycerides of $1,128 \mathrm{mg} / \mathrm{dl}$ at the time of this study. In the base-line plasma sample, apo $\mathrm{E}$ was present primarily in fraction II, with small amounts in fraction I (Fig. $7 c$ ), results similar to those of his brother. There was little apo $\mathrm{E}$ in fraction III. Apo CIII was present across a wide spectrum, including VLDL-, IDL-, and LDL-sized particles. There was little apo CIII in the HDL region (Fig. $7 d$ ). Heparin-induced lipolysis was associated with a $48 \%$ decrease in VLDL (fraction I) triglyceride concentration (Table III). There were reductions in apo. E and CIII in fraction I after heparin. Apo CIII was reduced and apo $\mathrm{E}$ was increased in fraction II. This increase in his fraction II apo E was less than that seen in his brother (subject 9). This was expected since less could be shifted to fraction II from the smaller relative content in fraction I before heparin injection. Apo $\mathrm{E}$ in fraction III also increased after heparin (Fig. 7 ; ; Table III), as did the content of apo CIII in HDL-sized particles (Fig. $7 d$ ).

Type $V$ subjects. Type $\mathrm{V}$ subjects had plasma triglyceride and cholesterol levels higher than those seen in type I subjects (Table I). Plasma LDL and HDL cholesterol were reduced relative to normal levels. Postheparin LPL and HTGL activity were within normal limits. The distributions of triglyceride, cholesterol, apoB, and apoA-I in one of the type $\mathrm{V}$ subjects are depicted in Fig. 8, $a$ and $b$. Both type $\mathrm{V}$ subjects had plasma levels of apo $\mathrm{E}$ and CIII that were increased relative to both normal and lipase-deficient subjects. Consistent with the presence of fasting hyperchylomicronemia, a major peak of apo $\mathrm{E}$ in these subjects was seen in the void volume (Fig $8 \mathrm{c}$ ). In contrast to findings in the LPL-deficient subjects, however, a broad peak of apo $\mathrm{E}$ was also found in VLDLsized particles and very little was present in the HDL, fraction III. Similarly, almost all of the plasma apo CIII and CII (Fig. $8, d$ and $e$ ) in these type $\mathrm{V}$ subjects was found in chylomicrons and VLDL, with negligible amounts in either intermediate or HDL-sized particles.

Type $\mathrm{V}$ subjects showed a substantial reduction in apo $\mathrm{E}$ in the chylomicron and VLDL fraction and a striking increase in apo $\mathrm{E}$ mass in fraction III after heparin administration. Again, no change in total plasma apo $\mathrm{E}$ was seen $15 \mathrm{~min}$ after heparin injection. As in all other subjects studied, the shift of apo E to fraction III was associated with an apparent increase in particle size of this lipoprotein fraction, as indicated by reduced elution volume (Fig. $8 c$ ). The apo CIII and CII profiles were altered similarly after heparin treatment (Fig. 8, $d$ and $e$ ). The mass of both apoproteins was reduced in chylomicron and VLDL and dramatically increased in HDLsized lipoproteins.

\section{Discussion}

In the present investigation we have attempted to gain some insight into the metabolic determinants of the lipoprotein 


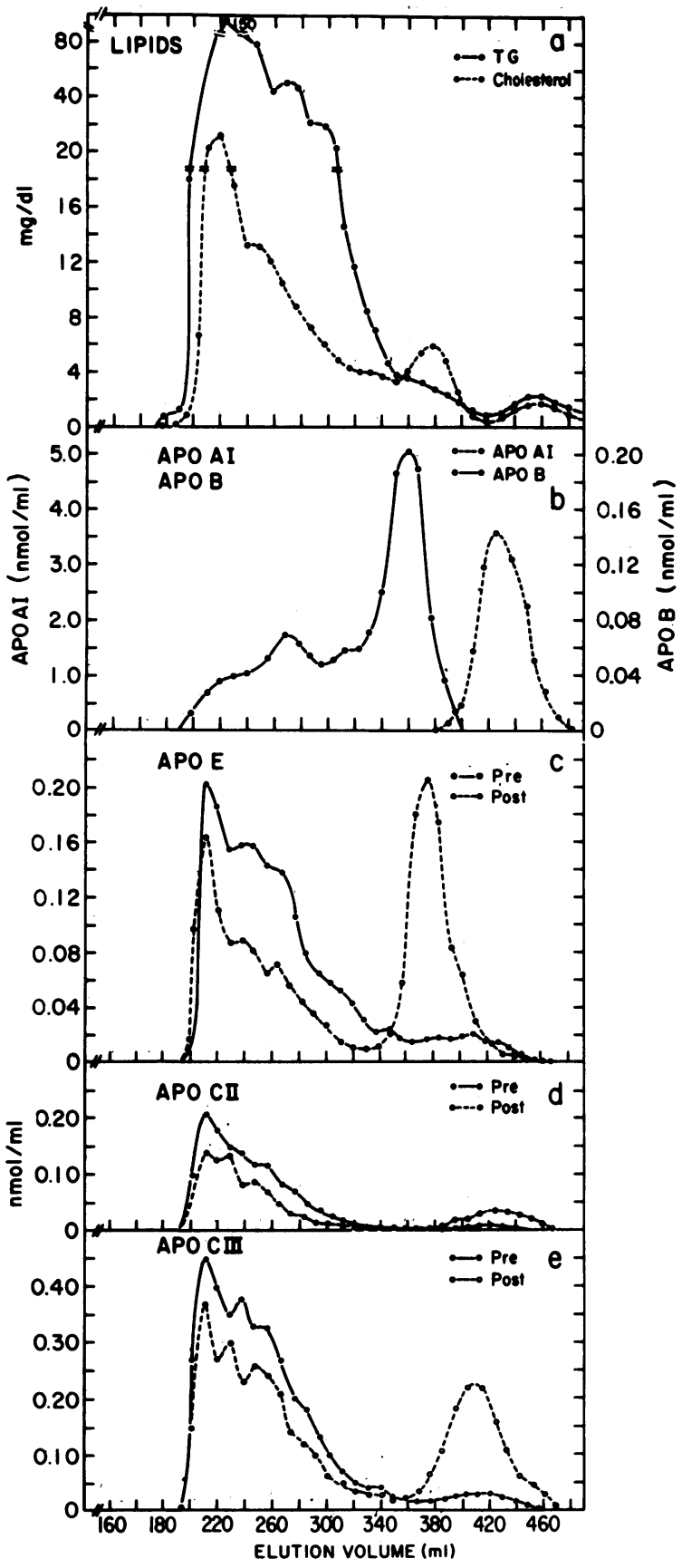

Figure 8. Lipid and apolipoprotein measurement in plasma of a subject with type $\mathrm{V}$ hyperlipoproteinemia (subject 10 ) after $4 \%$ agarose column chromatography. (a) Cholesterol and triglyceride are dominant in the chylomicron and VLDL regions. (b) Apo B and AI mark the positions of LDL and HDL, respectively, in preheparin plasma. Apo B also was relatively high in VLDL. The plasma levels and elution profiles of these apolipoproteins were unchanged after heparin administration. (c) In preheparin plasma, apo E was present almost exclusively in chylomicrons and VLDL. After heparin, plasma levels were unchanged $(122.2 \mathrm{vs} .118 .0 \mu \mathrm{g} / \mathrm{ml})$, but the proportion of apo $\mathrm{E}$ in fraction III showed a striking increase as this apolipoprotein declined in chylomicron and VLDL-sized particles. $(d)$ Apo CII was predominantly in triglyceride rich lipoproteins before heparin and was shifted to HDL $15 \mathrm{~min}$ after heparin, despite maintenance of constant plasma apo CII levels (299.4 vs. $303.7 \mu \mathrm{g} / \mathrm{ml}$ ). (e) Apo CIII in preheparin plasma was shifted from chylomicron- and VLDL- to HDL-sized lipoproteins after heparin administration. Total plasma levels were relatively constant $(700.1 \mathrm{vs.} 811.2 \mu \mathrm{g} / \mathrm{ml})$. association of apo E. For purposes of comparison we have also studied apo CII and CIII. The data presented confirm the recognized dynamic nature of the lipoprotein association of apo E, and of apo CII and CIII (7, 9, 31). In addition, they extend previous observations by suggesting that these apolipoproteins are associated with specific and metabolically independent subfractions of VLDL, IDL, and HDL.

The relative complements of these apolipoproteins in VLDL and HDL have been shown in the present study and in others $(5,32,33)$ to have a reciprocal relationship which is responsive to natural and induced $(7,32,33)$ perturbations of VLDL flux. In specific, in the normolipidemic and type $\mathrm{V}$ subjects studied (normal postheparin LPL and HTGL activity), redistribution of apo $\mathrm{E}$ from chylomicrons and VLDL to fraction III occuired $15 \mathrm{~min}$ after heparin-stimulated triglyceride hydrolysis. Similarly, apo CII and CIII were shifted to HDL. However, these observations cannot distinguish the individual roles of the two enzymes in apolipoprotein dynamics. The only previous study specifically exarhining changes in apo $\mathrm{E}$ after heparin induced lipolysis was also done in subjects with activities of both enzymes (7).

LPL is recognized as the initiator of triglyceride rich lipoprotein catabolism. Studies in vitro $(34)$ and in situ $(9,33)$ have provided evidence for a role for LPL in effecting the distribution of apo CII, CIII, and E. In vivo studies with an antibody blockade have strongly suggested that HTGL is also required for normal VLDL catabolism (15-17). Other studies, which used LPL-deficient subjects as a model for HTGL activity, showed that chylomicton triglyceride clearance is markedly reduced (35) but that VLDL triglyceride and apo B metabblism are less compromised $(11,35)$ when only HTGL activity is present. Studies that used the perfused liver are consistent with the catabolism of VLDL by HTGL (13). No studies, however, have attempted to relate HTGL activity to changes in apo $\mathrm{E}$ distribution among the plasma lipoproteins. The data reported in the present study strongly suggest that HTGL-mediated hydrolysis of triglyceride and/or phospholipid contributes significantly to the remodeling of apo E-containing VLDL and IDL and to the transfer of apo $E$ to an HDL subfraction(s) from triglyceride rich particles. The approach used in the present study has taken advantage of two clinical syndromes characterized by specific deficiencies of LPL or HTGL. Examination of the lipoprotein associations of apo $E$ and of the apo $\mathrm{C}$ peptides in these syndromes before and after the administration of heparin to accelerate the action of these enzymes has provided data consistent with differential effects of the two lipases on the distribution of these apolipoproteins.

The studies on four subjects with documented LPL deficiency support a primary role for LPL in the catabolism of apo C-containing lipoprotein, and suggest that LPL activity alone is not adequate for complete remodeling of apo Econtaining VLDL. If LPL activity were an absolutely unique preliminary to the formation of smaller apo E- or apo Ccontaining lipoproteins from VLDL, then it might be predicted that apo $\mathrm{E}$ and/or apo $\mathrm{C}$ would not be present in lipoproteins other than triglyceride rich lipoproteins in subjects lacking LPL. Apo CII and CIII were, in fact, present almost entirely in triglyceride rich chylomicrons and VLDL in LPL deficient subjects. In contrast, apo $\mathrm{E}$ was present as a major component of both chylomicrons and HDL-sized lipoprotein subfractions in the same subjects. Little or no apo $\mathrm{E}$ was present, however, 
in intermediate-sized lipoproteins. These data provide evidence that HTGL can independently mobilize apo E from triglyceride rich lipoproteins and that this enzyme is relatively ineffective in the removal of the $\mathrm{C}$ apoproteins. This interpretation is consistent with the dramatic increment in the apo $\mathrm{E}$ content of this HDL fraction after heparin administration in all LPLdeficient subjects with little or no change in the $\mathrm{C}$ apoprotein profiles.

The studies with HTGL-deficient subjects are also consistent with the suggestion that HTGL is an important contributor to the metabolism of apo E-containing intermediate-sized lipoprotein subfractions. Both subjects had proportionately large amounts of apo E in fraction II, relative to subjects with normal HTGL levels. After heparin administration both subjects demonstrated a reduction of apo $E$ in fraction I (VLDL) with an increase in fraction III, which suggests that LPL can effect a mobilization of apo E from VLDL to HDL in the presence of very low HTGL activity. However, the increments in apo E seen in fraction II strongly suggest that LPL alone is not enough to effect complete remodeling of intermediate-sized lipoproteins. In studies of other subjects with normal postheparin HTGL levels, the change in apo $E$ associated with fraction II was minimal (Fig. 3). These data would be consistent with either a direct transfer of apo E from VLDL to fraction III or with a flux through fraction II to III. Our observations, taken at four fixed times cannot distinguish between these possibilities. The accumulation of apo $E$ in fraction II in both subjects with documented HTGL deficiency, however, suggests that HTGL may normally play a role in maintaining a flux of apo $\mathrm{E}$ through these intermediate-sized particles.

In vitro studies have shown that chylomicrons are a better substrate for LPL than for HTGL, whereas smaller VLDL, IDL, and even LDL appear to be the preferred substrates of HTGL $(10,11)$. Size may play an additional role in vivo, resulting in the documented slowdown of chylomicron as compared with VLDL catabolism in LPL deficiency patients (35). These observations, taken with the data documenting independent metabolism of apo CIII and CII as opposed to apo E, are compatible with the model shown in Fig. 9. In this model, LPL hydrolyzes the triglycerides of chylomicrons and VLDL with release of the $C$ apolipoproteins, which are transferred to HDL with redundant surface material. This process may then expose areas rich in apo E to the action of HTGL. By hydrolyzing the triglyceride in intermediate sized particles, HTGL may then induce the transfer of apo E to a large HDL particle (fraction III). This model is consistent with the transfer of apo E from VLDL to fractions II and III in all subjects with both LPL and HTGL activity. It is also consistent with the near absence of fraction II in subjects deficient in LPL, since few if any LPL remnants are formed, and hydrolysis of VLDL and IDL by HTGL results in transfer of apo $E$ to HDL. The HTGL-deficient subjects, on the other hand, demonstrated an apparent accumulation of products of LPL action as fraction II, which cannot be processed by the HTGL pathway. The model allows for some direct transfer of apo $E$ from fraction I to fraction III by LPL action in these patients.

In view of the unchanged plasma levels of apo E, CII, and CIII $15 \mathrm{~min}$ after heparin-induced lipolysis, it seems reasonable to assume that a precursor-product relationship exists between these apolipoproteins in the triglyceride rich lipoproteins and in HDL. Another interpretation of these data is that a rapid

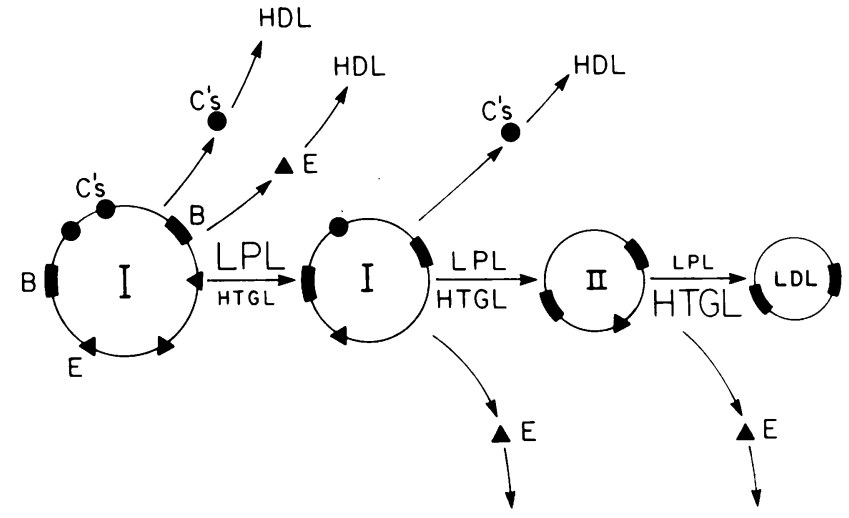

Figure 9. A proposed scheme for action of the lipase enzymes on VLDL. Large, triglyceride rich VLDL containing apo $E(E)$, apo $B$ (B), and the apo C proteins (C's) are good substrates for LPL and relatively poor substrates for HTGL. Concomitant with LPL-mediated triglyceride hydrolysis, the apo $\mathrm{C}$ peptides are transferred to HDL-sized particles with some apo E, converting the VLDL to a smaller lipoprotein relatively enriched in cholesterol and containing apo $\mathrm{E}$, apo $\mathrm{B}$, and some apo $\mathrm{C}$. This change in composition may make this intermediate a better substrate for HTGL but a less available substrate for LPL action. The continued action of HTGL on these lipoproteins may complete the remodeling to LDL with final transfer of apo E to HDL-sized lipoproteins (fraction III). The scheme suggests a preferential removal of the apo C by LPL and of apo E by HTGL. I, fraction I. II, fraction II.

clearance of apo E from VLDL was exactly balanced by a new influx into plasma HDL in all 11 subjects studied. The likelihood of this seems so remote that it has been discarded as a working hypothesis for now. Some direct removal of apo E-containing remnants may occur, however, resulting in a temporary fall in plasma apo E $60 \mathrm{~min}$ after heparin. Both in our studies and the previous study by Blum (7), total plasma apo $E$ had diminished at this time. Nestel et al. (32) found a dramatic reduction in the mass of the $\mathrm{C}$ peptides after heparin administration concomitant with their redistribution from VLDL to HDL. Our data do not confirm this loss of the C apolipoproteins, even in the most hypertriglyceridemic subjects, although they do document the redistribution. Nestel et al. suggested that this loss represented an active pathway for direct remnant removal, and it is possible that patients differ in the activity of this pathway. Alternatively, the discrepancy could represent differences between the effects of pulse (present study) and constant infusion (32) of heparin.

Fraction III is probably not a homogeneous group of lipoproteins but rather represents an array of lipoproteins containing varying proportions of apo E, CIII, CII, and AI (as well as other apolipoproteins not measured). Evidence for this heterogeneity in composition includes the consistent asymmetry of the apo E profile in the HDL region. Apo E-phospholipid complexes released from chylomicrons and VLDL as a result of LPL- and/or HTGL-mediated hydrolysis induced by heparin administration may associate preferentially with larger preexisting HDL subfractions, leading to a shift in the apparent size of the whole apo E-containing fraction. Apo $\mathrm{E}$ is known to associate with large HDL both in vivo under conditions of cholesterol feeding (36) and in vitro under conditions in which cholesterol delivery to serum is enhanced (37). With accelerated 
release of VLDL surface constituents, including free cholesterol, an analogous association may occur. Alternatively, the apo E may be released from VLDL and chylomicrons in association with a lipoprotein complex slightly larger than the average HDL particle.

Other studies have provided evidence for a role for HTGL in the conversion of $\mathrm{HDL}_{2}$ to $\mathrm{HDL}_{3}$. In rats, the administration of anti-HTGL resulted in the accumulation of $\mathrm{HDL}_{2}(38,39)$. Conversely, the incubation of human serum with rat HTGL led to a decrease in $\mathrm{HDL}_{2}$ constituent cholesterol and phospholipid and a parallel rise in $\mathrm{HDL}_{3}(40)$. In vivo studies in LPL-deficient patients also showed that the heparin infusion resulted in increased phospholipid and total protein in $\mathrm{HDL}_{3}$ at the expense of $\mathrm{HDL}_{2}$ (41). Although these data seem inconsistent with our observation of an apparent increase in the size of the HDL subfraction enriched in apo $E$, the fact remains that we have specifically focused on shifts of apo $E$, whereas these cited studies all described changes in the cholesterol, phospholipid, and total protein profiles. The apo E enriched subclass represents only a small proportion of the total cholesterol, phospholipid, and protein present across the HDL spectrum (42).

This in vivo study in humans provides evidence for parallel and complementary roles for LPL and HTGL in triglyceride rich lipoprotein catabolism. Their effects on the flux of the apolipoproteins involved in this process, however, suggest that the individual enzymes have unique interactions with each of these apolipoproteins. Fig. 9 summarizes our concepts of the metabolic pathways describing the catabolism of VLDL and the parallel roles of the two postheparin lipases. Both HTGL and LPL can independently cause a redistribution of apo $\mathrm{E}$ from chylomicrons and VLDL to smaller lipoproteins. Only HTGL, however, may mobilize apo E from catabolic products of intermediate size, whereas LPL hydrolysis may be a necessary preliminary to transfer of the $\mathrm{C}$ apolipoproteins.

\section{Acknowledgments}

We are grateful for the excellent technical assistance of Ms. Nora Ngai, Ms. Laurie Goldman, Ms. Tung Chang Han, and Ms. Rebecca Veiss. We also appreciate the assistance of Ms. Marion Shiffer in the preparation of the manuscript.

This work was supported by grants HL23077, HL30435, and RR71 from the National Institutes of Health (General Clinical Research Centers Branch) and grant 81-925 from the American Heart Association.

\section{References}

1. Weisgraber, K. H., S. C. Rall, Jr., and R. W. Mahley. 1981 . Human $\mathrm{E}$ apoprotein heterogeneity. Cysteine-arginine interchanges in the amino acid sequence of the apo $\mathrm{E}$ isoforms. J. Biol. Chem. 256:9077-9083.

2. Schneider, W. T., P. T. Kovanen, M. S. Brown, J. L. Goldstein, G. Utermann, W. Weber, R. J. Havel, L. Kotite, J. P. Kane, T. L. Innerarity, and R. W. Mahley. 1981. Familial dysbetalipoproteinemia. Abnormal binding of mutant apoprotein $\mathrm{E}$ to low density lipoprotein receptors of human fibroblasts and membranes from liver and adrenal of rats, rabbits, and cows. J. Clin. Invest. 68:1075-1085.

3. Havel, R. J., L. Kotite, J.-L. Vigne, J. P. Kane, P. Tun, N. Phillips, and G. C. Chen. 1980. Radioimmunoassay of human arginine rich apolipoprotein, apoprotein E. J. Clin. Invest. 66:1351-1362.

4. Kushwaha, R. S., W. R. Hazzard, P. W. Wahl, and J. J. Hoover.
1977. Type III hyperlipoproteinemia: diagnosis in whole plasma by apolipoprotein E immunoassay. Ann. Int. Med. 87:509-516.

5. Blum, C. B., L. Aron, and R. Sciacca. 1980. Radioimmunoassay studies of human apolipoprotein E. J. Clin. Invest. 66:1240-1250.

6. Gibson, J. C., A. Rubinstein, P. R. Bukberg, and W. V. Brown. 1983. Apolipoprotein $E$ enriched lipoprotein subclasses in normolipidemic subjects. J. Lipid Res. 24:886-898.

7. Blum, C. B. 1982. Dynamics of apolipoprotein E metabolism in humans. J. Lipid Res. 23:1308-1316.

8. Patsch, J. R., A. M. Gotto, Jr., T. Olivecrona, and S. Eisenberg. 1978. Formation of high density lipoprotein-like particles during lipolysis of very low density lipoproteins in vitro. Proc. Natl. Acad. Sci. USA. 75:4519-4523.

9. Tam, S. P., L. Dory, and D. Rubinstein. 1981. Fate of apolipoproteins CII, CIII and E during lipolysis of human very low density lipoproteins in vitro. J. Lipid Res. 22:641-651.

10. Eisenberg, S., and R. I. Levy. 1975. Lipoprotein metabolism. Adv. Lipid Res. 13:2-80.

11. Nicoll, A., and B. Lewis. 1980. Evaluation of the roles of lipoprotein lipase and hepatic lipase in lipoprotein metabolism: in vivo and in vitro studies in man. Eur. J. Clin. Invest. 10:487-495.

12. Musliner, T. A., P. N. Herbert, and M. J. Kingston. 1979. Lipoprotein substrates of lipoprotein lipase and hepatic triglyceride lipase from human postheparin plasma. Biochem. Biophys. Acta. 575:277-288.

13. Berry, E. M., R. Aldini, H. Bar-on, and S. Eisenberg. 1981. Role of the liver in the degradation of very low density lipoproteins: a study of lipolysis by heparin releasable liver lipase and uptake during isolated rat liver perfusion. Eur. J. Clin. Invest. 11:151-159.

14. Turner, P. R., N. E. Miller, C. Cortese, W. Hazzard, J. Coltart, and B. Lewis. 1981. Splanchnic metabolism of apo B. Studies of arteryhepatic vein differences of mass and radiolabel in fasted human subjects. J. Clin. Invest. 67:1678-1686.

15. Grossen, J., O. Schrecker, and H. Greten. 1981. Function of hepatic triglyceride lipase on lipoprotein metabolism. J. Lipid Res. 22:437-442.

16. Murase, P., and H. Ikatura. 1981. Accumulation of intermediate density lipoprotein in plasma after intravenous administration of hepatic triglyceride lipase antibodies in rats. Atherosclerosis. 9:293300.

17. Goldberg, I. J., N.-A. Le, J. R. Paterniti, Jr., H. N. Ginsberg, F. T. Lindgren, and W. V. Brown. 1982. Lipoprotein metabolism during acute inhibition of hepatic triglyceride lipase in the cynomolgus monkey. J. Clin. Invest. 70:1184-1192.

18. Mordasini, R., F. Frey, W. Flury, G. Klose, and H. Greten. 1977. Selective deficiency of hepatic triglyceride lipase in uremic patients. N. Engl. J. Med. 297:1362-1366.

19. Abrams, J. J., S. M. Grundy, and H. Ginsberg. 1981. Metabolism of plasma triglycerides in hypothyroidism and hyperthyroidism in man. J. Lipid Res. 22:307-322.

20. Muller, P., R. Felline, J. Lambrecht, B. Agostini, H. Wieland, W. Rost, and D. Seidel. 1974. Hypertriglyceridemia secondary to liver disease. Eur. J. Clin. Invest. 4:419-428.

21. Nestel, P. J., N. H. Fidge, and M. H. Tan. 1982. Increased lipoprotein remnant formation in chronic renal failure. N. Engl. J. Med. 307:329-333.

22. Breckenridge, W. C., J. A. Little, P. Alaupovic, C. S. Wong, A. Kakis, G. Kakos, F. Lindgren, and G. Gardiner. 1982. Lipoprotein abnormalities associated with a familial deficiency of hepatic lipase. Atherosclerosis. 45:161-179.

23. Baginsky, M. L., and W. Virgil Brown. 1979. A new method for measurement of lipoprotein lipase in postheparin plasma using SDS for inactivation of hepatic triglyceride lipase. J. Lipid Res. 20:548556.

24. Allain, C. C., L. S. Pooru, S. C. G. Chan, W. Richmond, and P. C. Fu. 1974. Enzymatic determination of total serum cholesterol. Clin. Chem. 20:470-475. 
25. Bucolo, G., and H. David. 1973. Quantitative determinations of serum triglycerides by the use of enzymes. Clin. Chem. 19:476-482.

26. Finley, P. R., R. B. Schifman, R. J. Williams, and D. R. Lichti. 1978. Cholesterol in high density lipoproteins: use of $\mathrm{Mg}^{++} /$dextran sulfate in its enzymatic measurement. Clin. Chem. 24:931-933.

27. Bukberg, P. R., N.-A. Le, H. N. Ginsberg, J. C. Gibson, L. C. Goldman, and W. V. Brown. 1983. Direct measurement of apoprotein CIII specific activity in ${ }^{125}$ I labeled very low density lipoproteins using immunoaffinity chromatography. J. Lipid Res. 24:1251-1260.

28. Le, N.-A., J. S. Melish, B. C. Roach, H. N. Ginsberg, and W. V. Brown. 1978. Direct measurements of apo B specific activity in ${ }^{125}$ I labeled lipoproteins. J. Lipid Res. 19:570-584.

29. Weidman, S. W., B. Suarez, J. M. Falko, J. L. Witztum, J. Kolar, M. Raben, and G. Schonfeld. 1979. Type III hyperlipoproteinemic development of a VLDL apo E gel isoelectric focusing technique and application in family studies. J. Lab. Clin. Med. 93:549-569.

30. Heiss, G., I. Tamir, C. E. Davis, H. A. Tyroler, B. M. Rifkind, G. Schonfeld, D. Jacobs and I. Frantz. 1980. Lipoprotein cholesterol distributions in selected North American populations. Circulation. 61: 302-315.

31. Weisgraber, K. H., R. W. Mahley, and G. Assmann. 1977. The rat arginine-rich apoprotein and its redistribution following injection of iodinated lipoproteins into normal and hypercholesterolemic rats. Atherosclerosis. 28:121-140.

32. Nestel, P. J., M. W. Huff, T. Billington, and N. H. Fidge. 1982. Changes in the plasma lipoprotein distribution of apolipoproteins $\mathrm{CII}$, CIII, $\mathrm{CIII}_{2}$ and apolipoprotein $\mathrm{B}$ after heparin induced lipolysis. Biochim. Biophys. Acta. 712:94-102.

33. La Rosa, J. C., R. I. Levy, W. V. Brown, and D. S. Fredrickson. 1971. Changes in high density lipoprotein composition after heparin induced lipolysis. Am. J. Physiol. 220:785-791.
34. Eisenberg, S., and T. Olivecrona. 1979. Very low density lipoprotein. Fate of phospholipids, cholesterol and apolipoprotein C during lipolysis in vitro. J. Lipid Res. 20:614-623.

35. Quarfordt, S. H., A. Frank, D. M. Shames, M. Berman, and D. Steinberg. 1970. Very low density lipoprotein triglyceride transport in type IV hyperlipoproteinemia and the effects of carbohydrate rich diets. J. Clin. Invest. 249:2281-2297.

36. Mahley, R. W. 1981. Atherogenic hyperlipoproteinemia. The cellular and molecular biology of plasma lipoproteins altered by dietary fat and cholesterol. In Medical Clinics of North America: Lipid Disorders. Vol. 66. R. J. Havel, editor. Academic Press, New York. 375-402.

37. Gordon, V., T. L. Innerarity, and R. W. Mahley. 1983. Formation of cholesterol and apoprotein E-enriched high density lipoproteins in vitro. J. Biol. Chem. 258:6202-6212.

38. Kuusi, T., P. K. J. Kinnunen, and E. A. Nikkila. 1979. Hepatic endothelial lipase antiserum influences rat plasma low and high density lipoproteins in vivo. FEBS (Fed. Eur. Biol. Soc.) Lett. 104:384-388.

39. Jansen, H., A. Vantol, and W. C. Hulsmann. 1980. On the metabolic function of heparin releasable liver lipases. Biochem. Biophys. Res. Commun. 92:53-59.

40. Groot, P. H. E., L. M. Scheek, and H. Jansen. 1983. Liver lipase and high density lipoprotein. Lipoprotein changes after incubation of human serum with rat liver lipase. Biochim. Biophys. Acta. 751:393410.

41. Rao, S. N., C. Cortese, N. E. Miller, Y. Levy, and B. Lewis. 1982. Effects of heparin infusion on plasma lipoproteins in subjects with lipoprotein lipase deficiency. FEBS (Fed. Eur. Biol. Soc.) Lett. 150:255-259.

42. Gibson, J., A. Rubinstein, and W. V. Brown. 1985. Isolation of apo E containing lipoproteins by affinity chromatography. Methods Enzymol. In press. 